\title{
Infographics: Absent Without Leave
}

\author{
Ian Mitchell \\ Liverpool John Moores University, School of Art and Design, Liverpool, UK \\ i.mitchell@ljmu.ac.uk
}

\begin{abstract}
It is widely regarded by cultural commentators that we are in a period of unprecedented political uncertainty, in which there is a desire for simple explanations to the complex sociopolitical challenges of 21st Century. It might be argued that in this climate a mode of communication such as infographics would have considerable currency - especially within the context of interpreting and understanding the competing and contradictory political views that often reference complex data and statistics. Infographics have always attempted to make the visualisation of information easy and accessible to ordinary people whilst maintaining an objectivity and factual accuracy, articulated in the work of the Isotope Movement and the celebrated examples by William Playfair, Florence Nightingale and Thomas Clarkson. Other examples such as The Daily Express newspaper's Expressographs of the mid 1950s promoted the political bias of its owner and were little more than news propaganda masquerading as informative graphics. Whether it's objective explanation, communicating a sociopolitical cause or belief, or outright deception and propaganda, infographics have been a central communication tool for many years. However this research finds an almost complete absence of infographics used during the 2017 UK General Election across a variety of communication media channels. This paper questions whether infographics have a place anymore in communicating political ideas and beliefs and whether this represents an emerging irrelevance (or death) of one of graphic design's most significant visual languages. Are we entering a post-truth, post-facts, post-infographics era? This research will focus on an analysis of communication content published during the 2017 UK General Election, ranging from traditional printed newspapers and official political party publications to unofficial online and social media output. The results presented will determine the extent of infographics diminishing value and relevance and offer some possible reasons for this phenomenon.
\end{abstract}

Keywords: Infographics / political graphics / propaganda

\section{Introduction}

In Spring 2017 a general election was called in the UK bringing into sharp focus the practice of communicating complex "social and economic matters to ordinary people". [1] It was hoped that the period of election campaigning would offer a 
defined sample of politically and socially motivated infographics to analyse. This analysis would aim to measure the quantity and quality of infographics. From preliminary research examples of infographics appeared hard to find. Does this indicate an emerging irrelevance of one of graphic design's most significant visual languages in communicating political ideas and beliefs?

\section{Methodology}

This research employs one main methodology: the analysis of communication content published during the UK General Election campaign, ranging from traditional newspapers, their online versions, official Political Party manifestos, and their twitter feeds, and finally what could be found across other less official social media. This broad and varied approach was taken to acknowledge the recent and ongoing shifts in how news and political debate is published, consumed and shared. For each communication channel the type of visual content was counted and the use of infographics reviewed.

Printed newspapers. Three daily newspapers and their Sunday equivalents from across the political spectrum were surveyed the weekend preceding the election to give an initial snapshot of traditional printed news. The Guardian and Observer from the broadsheet left, the Mirror from the tabloid left, the Express from the tabloid right, and the specialist economic broadsheet the Financial Times. This was by no means an extensive sample, however it was hoped that this cross section of newspapers would return some examples of infographics. The Guardian is well known for its use of infographics and data journalism, [2] whilst the Express has a history of using infographics know as "Expressographics" for propaganda purposes in the 1950s. [3]

Online newspapers. A survey of the printed newspapers' online versions allowed for analysis across a longer period of time. Each newspapers' General Election sections were reviewed for articles available in the seven days preceding the election.

Manifestos. Political party manifestos were analysed as the official published declaration of the ideas, beliefs and policies of the six main parties; The Conservative Party, Labour, Liberal Democrats, The Green Party, SNP (Scottish National Party) and UKIP (UK Independence Party).

Twitter. A survey of the six main parties' official twitter feeds extended the analysis of official party communication into the less formal and more immediate channel of social media and how infographics may be used in response to unfolding campaign events. Twitter's built-in Advanced Search facility allowed an analysis of each party's twitter feed for the entire duration of the campaign - from $19^{\text {th }}$ April 2017 when the election was called until $7^{\text {th }}$ June 2017 when campaigning stopped. 
Other social media. The influence of social media on election campaigning is well documented now, even if its extent and influence is still being debated. Recent allegations place Cambridge Analytica and Facebook at the centre of a scandal in which political organisations targeted voters with personalised political advertisements during the Brexit campaign by harvesting 50 million Facebook profiles without permission. [4] However, defining a sample to analyse for a social media channel such as Facebook is complicated. A key feature of Facebook is that it feeds us what we are already interested in, making it hard to analyse it with any sure objectivity. The analysis of election related posts in the week preceding the election was inevitably trapped in the researcher's bubble. A general Facebook Posts search for "UK General Election 2017 infographics" was made in the hope of returning a broader and more objective sample to analyse.

\section{Coding Units}

The following coding units were identified: the articles, posts or pages; photographic images; videos; graphics; infographics and info-animations. For the purpose of this analysis the following define the less explicit coding units:

Graphics. Designed images, typically featuring a combination of photography, graphics and/or typography.

Infographics. Designed images featuring elements associated with traditional infographics such as pictograms, charts, diagrams and displays of data.

Info-animations. Videos or moving images that contains some elements of infographics.

Similar coding units were identified for the analysis of each communication channel.

\section{Findings}

To summarise, less than $4 \%$ of all the content analysed could be coded as infographics or info-animation. Figure 1 shows the breakdown across media channels: Printed newspapers $0.5 \%$, online newspapers $16 \%$, Party manifestos $0 \%$, Party twitter feeds $1.6 \%$ and Facebook $6 \%$. 


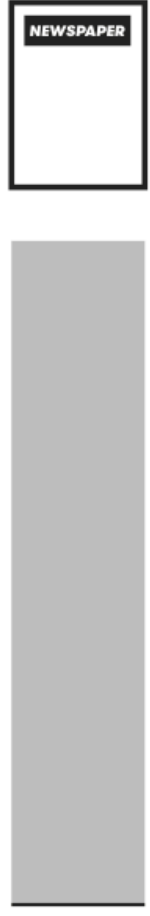

$0.5 \%$
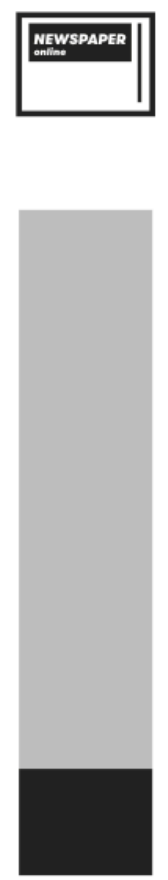

$16 \%$
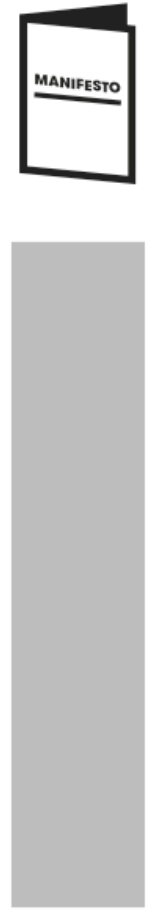

$0 \%$
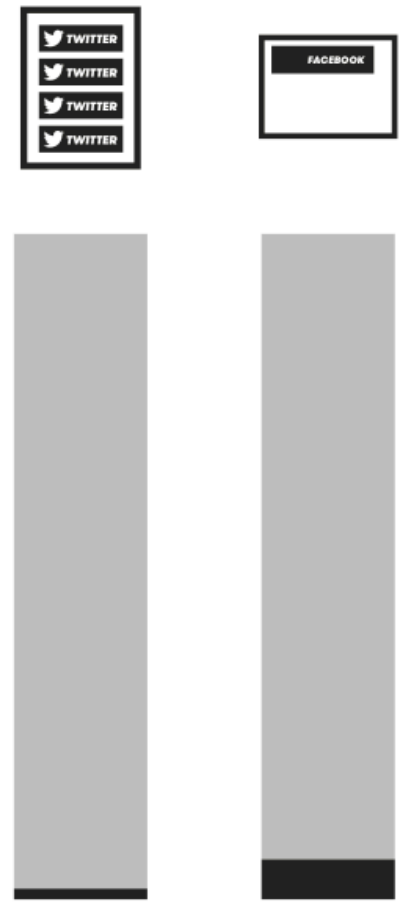

$1.6 \%$

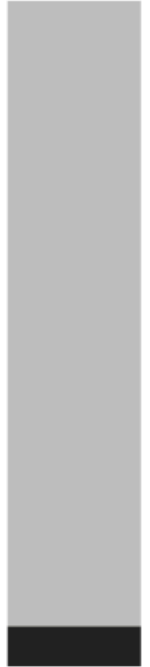

$6 \%$

Fig. 1. Chart showing the percentage of info-graphics counted across media channels.

The almost complete absence of infographics in the printed newspapers was a surprise, and did prompt the broadening of research to other media. There were just eleven uses of infographics across the seven newspapers, and only one example that could be considered to have anything to do with the election; a poll of polls and political map from the Observer.

The online newspapers featured infographics more significantly. Express online and Guardian online had the highest proportion of infographics. The examples of the Guardian graphics were neat, tidy and workmanlike but somewhat disappointing for a newspaper that is renowned for its use of infographics. However they did contain genuine information that could help interpret policy. Although Express online featured the highest proportion of infographics, almost all were about the polls and all were originated by other sources such as YouGov, IPSOS More, ICM, britainelects.com. The closest they came to presenting something more editorial was the reposting of a BBC report, which contained unnecessary contextualization that reduced the piece to a satirical parody of news graphics, or "chart-junk". [5] The Financial Times clearly placed the greatest emphasis on a design led approach to their online articles with a variety of illustrative work and adventurous data 
visualisation. However, like Express online, these tended to focus on explanation of the polls and the political system, not on policy. For example, one nicely produced info-animation explained the political system rather than issues or debates. The tone of the content felt a little patronising considering the likely extent of the audience's political engagement. The FT online requires a subscription for example, which possibly accounts for the richly designed content on the site.

Infographics were conspicuous by their complete absence in the party manifesto documents. Not one was featured. Instead, a variety of well-worn visual clichés were used to illustrate or signify each party's policies and beliefs. Ironically many of these signifiers were shared across the political spectrum.

The twitter feeds of the parties did register some use of infographics, although quite insignificant in terms of the proportion of overall tweets (see figure 2), especially considering the generous interpretation of the definitions of infographics and info-animations being used to identify the coding units. Many of the examples coded as info-animations featured superficial infographics used for decoration rather than visual explanation. At best the style (or language) of infographics was being used as possible shorthand for facts, where very little data or information was being presented.
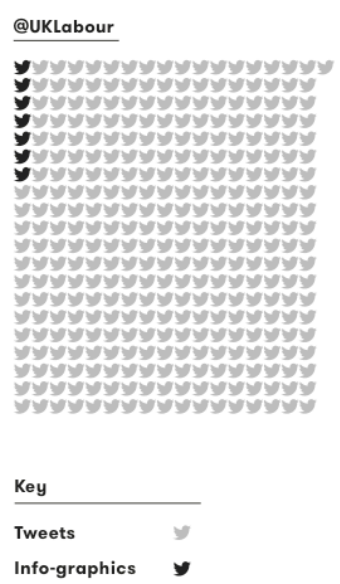
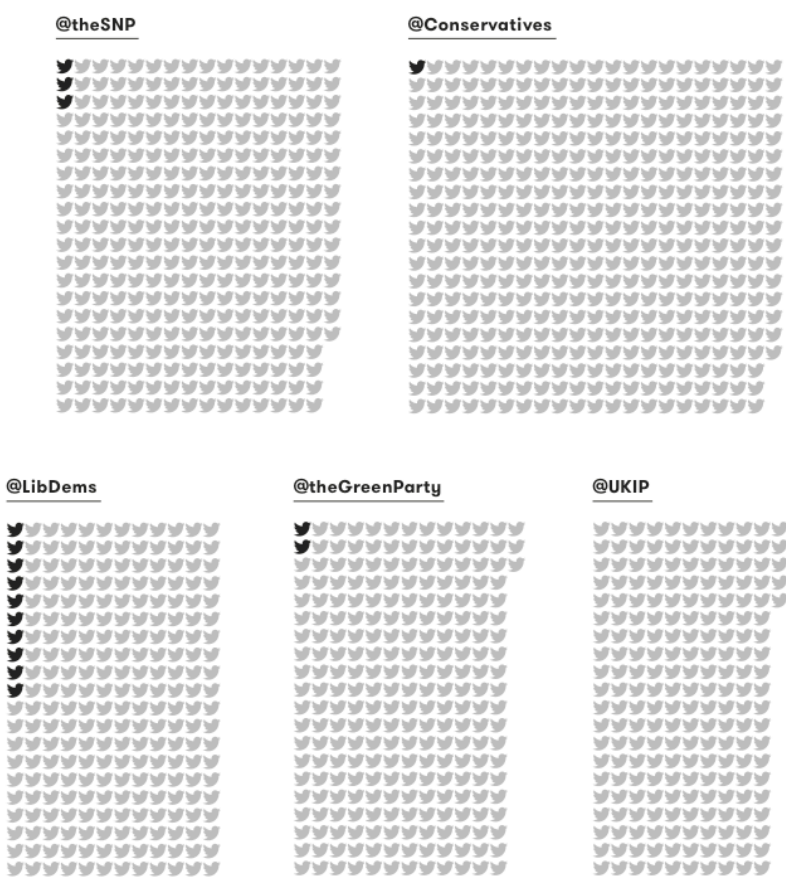

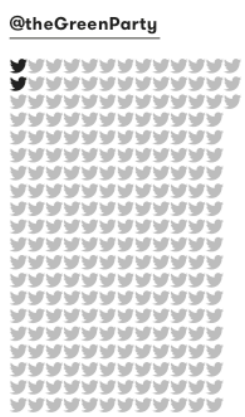

Fig. 2. Chart showing the proportion of info-graphics counted across Party Twitter feeds. 
From the analysis of the researcher's Facebook newsfeed, the Alt-Left online media publication Another Angry Voice was particularly evident. Its Facebook site, styled on an old-fashioned blog, reaches millions of people with a "combination of endearingly homemade memes, Facebook-friendly headlines, and a regular output of relentlessly anti-Conservative takes on the news". [6] Out of 243 posts during the election campaign the majority featured either graphics or video, of which 15 (6\%) could be coded as infographics. "What's striking is the extent to which the new alt-left sites can appear remarkably similar in tone and approach to their arch-enemies... using the same tabloid tactics to reach the maximum number of people and putting a heavy spin on quotes and statistics." [7] The three most shared posts featuring infographics use a no frills anti-design approach which has become a part of Another Angry Voice's authentic brand.

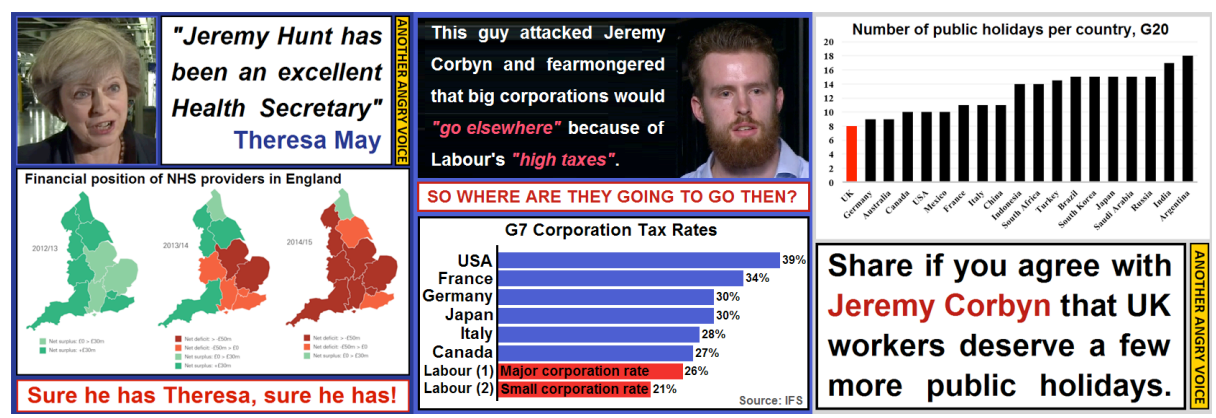

Fig. 3. Images from: https://www.facebook.com/Another-Angry-Voice-185180654855189. Another Angry Voice.

Although the general Facebook Posts search for "UK General Election 2017 infographics" produced few results it did uncover one notable example by a recent design graduate Daniel Britton. The info-animation for Momentum (the grassroots campaigning movement for Labour's left-wing) illustrates the direction the UK has taken over the past 7 years, presenting 10 facts using a minimal modernist design aesthetic with a level of sophistication between form and content that was hard to find in the rest of this research. 


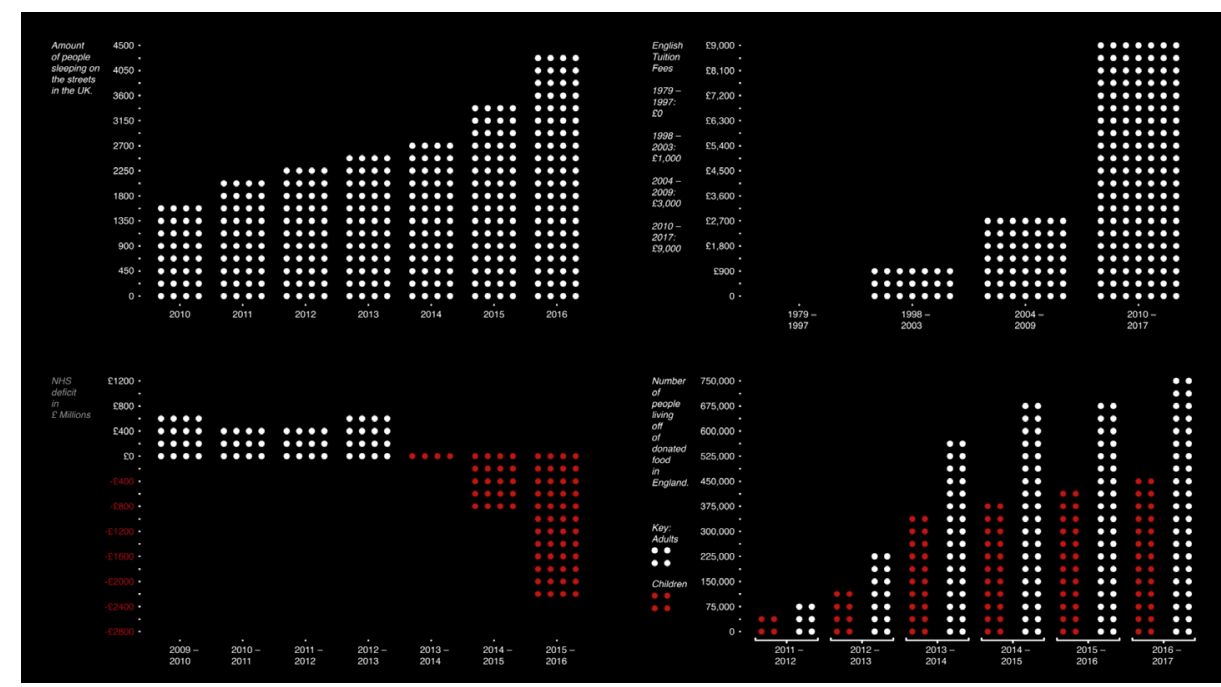

Fig. 4. Frames from 'UK General Election 2017 infographics'. Daniel Britton.

Daniel Britton was questioned about the authorship of the work (Britton, personal communication, October 27, 2017):

"So what happened with the project is that I had so much passion for creating awareness about the current political climate I produced the info-graphic off my own back. I created a narrative and once I had the story I wanted to tell I sourced the information (all from government websites or respected charities) and once I designed it I then contacted anyone that would of been interested to listen and begged for them to look it over. Of course because I am a small name designer $99 \%$ of people will ignore you but Momentum were open to the idea and in a few places even assisted me with the research. Once Momentum posted the piece it got 50,000 views in 2 days and the design gained a new weight."

\section{Discussion}

Is $4 \%$ a good or appropriate amount of content analysed to be considered infographics or info-animation? It's hard to say without comparing these results with a different sample - a previous general election campaign or a campaign from another country for instance.

Infographics are in evidence but primarily online. Although this may be an indicator of the pre-eminence of this media now, the dearth of infographics in printed newspapers is disappointing considering that print offers the time for a reader to slow down and properly interrogate an infographic. This criticism can also 
be levelled at the party manifestos. These long form documents, dense with policy data and factual evidence would all surely benefit from visual explanations in the form of infographics. However, across the manifestos or social media, very few parties valued a design led graphic approach let alone a sophisticated or creative use of infographics.

Why is it that there weren't more examples like Daniel Britton's infographic? Looking beyond the parameters of the election there are impressive examples of contemporary socio-political infographics, such as Antti Lipponen's The Temperature Circle (2017). His info-animation posted and shared across Twitter shows the rhythm of global warming for countries around the world, from Afghanistan to Zimbabwe. It unequivocally presents the argument that global warming is a very real and urgent problem. Lipponen said he made the animation because he wanted a "nice looking, clear, and informative" [8] way to convey that information in a way people can understand.

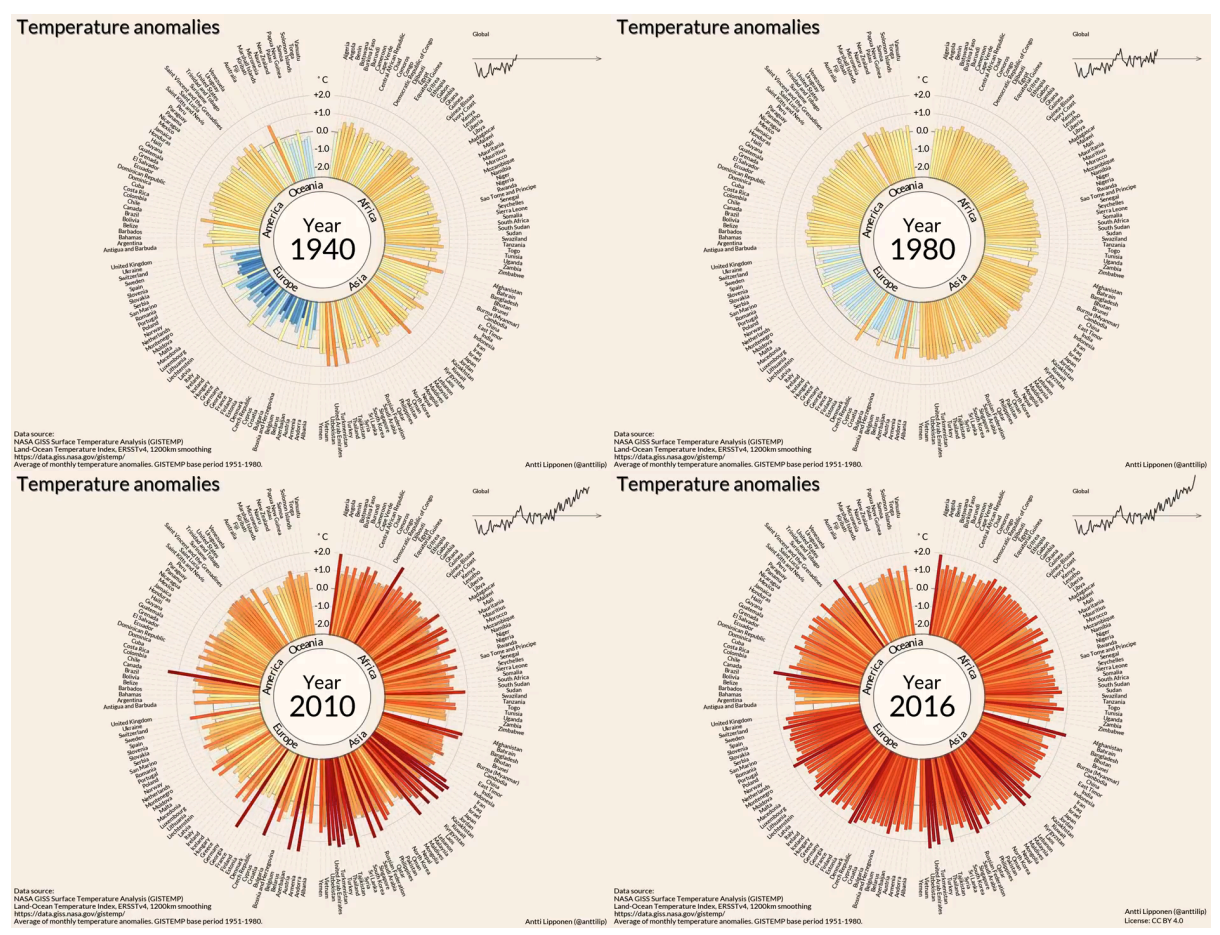

Fig. 5. Frames from 'The Temperature Cycle'. Antti Lipponen.

Lipponen is a physicist at the Finnish Meteorological Institute. Perhaps this is a clue to the absence of quality infographics found in this research. Who are the authors of the graphics - hired hands? Do they really have personal interest in the issues? Are they personally motivated to convey information in an understandable way? 
Lipponen isn't a graphic designer or an information designer, yet he's taken of Isotype's role of the "transformer" [9] to turn data into a persuasive graphic because he had wanted to explain something. Similarly Daniel Britton's animations were made "off his own back". He had a story to tell, sourced the information and then self-published the infographic which was then picked-up by an official channel.

\section{Conclusion}

Is it a surprise that an election campaign featured a dearth of quality infographics? Election campaigns rarely produce quality political debate in other communication formats, whether it's news reporting or party political broadcast, so why should infographics be any different.

This research unashamedly focused on the UK and in most cases official sources, which is certainly a limitation. Hopefully, if repeated in another country it might produce very different results. If not, we may have a crisis for one of graphic design's most significant visual languages to reflect the current political crises.

\section{References}

1 Kindel, E and Walker, S. (2010). Isotype Revisited. Retrieved from: http://isotyperevisited.org/2010/09/isotype-revisited.html assessed 2017

2 Rogers, S. (2011). Facts Are Sacred: The Power of Data. London, UK: Guardian Books.

3 Dick, M. (2015). Just Fancy That. Journalism Studies, 16:2, 152-174. Oxford: Routledge. DOI: 10.1080/1461670X.2013.872415

4 Greenfield, P, (2017, March). The Cambridge Analytica files; the story so far. Retrieved from: https://www.theguardian.com/news/2018/mar/26/the-cambridge-analytica-filesthe-story-so-far theguardian.com

5 Tufte, E. (2001). The Visual Display of Quantitative Information. Connecticut, USA: Graphics Press.

6 Waterson, J. (2017, May). The Rise Of The Alt-Left British Media. Retrieved from: https://www.buzzfeed.com/jimwaterson/the-rise-of-the-altleft?utm_term=.cbQMzY310j\#.stQldxkyWB

7 ibid

8 Lipponen, A. as cited in Kahn, B. (2017, August). A Century of Global Warming, in Just 35 Seconds. Retrieved from: https://www.scientificamerican.com/article/a-century-of-globalwarming-in-just-35seconds $/$ ?utm_source=twitter\&utm_medium=social\&utm_campaign=sa-editorialsocial\&utm_content $=\& u t m \_t e r m=\&$ sf104473521 $=1$

9 Kinross, K. (2009). The Transformer - Principles of Making Isotype Charts. London, UK: Hyphen Press. 